\title{
PREOPERATIVE EXAMINATION AND PREPARATION OF PROBLEM PATIENTS ${ }^{1}$
}

\section{Stanislaw B. Donigiewicz, M.D., F.A C A ${ }^{2}$}

TODAI's WIDENING SCOPE of surgery, allowing help' to even the poorest of "risks" depends on team-work. The problenrs are discussed by all who can bring their special knowledge into play. The anaesthetıst should not and cannot be missing from this team and must be as conversant in present-day medical knowledge as the best on the team

Interference with the proper function of the cardio-respiratory system and crrculatory system due to disease or injury constitutes the most commonly encountered problems in anaesthetıc practice. Closely related are problems arising from disturbed fluid and electrolyte balance and from altered body resistance to stress

This division, of course, is an artificial one, as actually they may all be present at the same time or merge from one into another if unattended, furthermore, this grouping does not include all the diverse problems which crop up in anaesthetic practice

An endeavour is made to cover the most frequently encountered problems, to illustrate them by pertinent cases and to group them only for the sake of clarity

\section{RESPIRATORY SYSTEM}

The gas exchange in the lungs is commonly imparred by a combination of inadequate aeration or perfusion Interference with the bellows action of the lungs and respiratory muscles may result from the depression of the driving mechansm (respiatory centre), inflammatory, neoplastic and degenerative disease of lungs and bronchi, changes in the thoracic cage caused by disease, degeneration or trauma The results are disturbed relationship between the amounts of air present $m$ the lungs and the amount of fresh air entermg the alveoli at rest and durmg the exercise; reduction of 1 espiratory reserve avalable to an mdividual at the moment of stress, changed pressure relationshup between the intra-pleural space and the atmosphere

Well-ventilated alveols may fall as respiratory units if pulmonary circulation is madequate The latter may be the result of the reduced number of patent capillaries, sluggish circulation due to a failing heart (usually' associated with pulmonary hypertension), and the reduced amount of circulating blood volume and haemoglobin due to haemonhage and shock

The respuratory system is usually examined together with the cardiovascular system, and a statement "heart and lungs normal or negative" is made. When abnormal, a listmg of abnormal signs and symptoms usually follows. The importance of the pre-ancesthetic visit lies in the evaluation of the patient as a risk.

${ }^{1}$ Read at the Nova Scotia Division of Canadian Anaesthetists' Socrety Annual Meeting held on April 15, 1957, at Victorid General Hospital, Halifax, N S

2st Martha's Hospital, Antigonish, NS 
In other words, one endeavours to estımate patient $s$ reserve to withstand drugging of the respiratory centre, interference with respiratory excursions of the diaphragm and the thorax by abnormal positions and use of relaxants, periods of relative or complete respiratory obstruction, haemorrhage, etc.

Many tests have been devised to measure practically all phases of ventilation and perfusion, but most of them are time-consuming and require equipment not ordinarily avaulable.

Two simple tests allowing measurement of ventilating capacity of an individual, requiring minimurn preparation and only standard spirometric equipment are avallable (1). They are the "Timed Vital Capacity Test," and the "Maximal Breathing Capacity Test." Vital capacity, although useful in measuring changes in the same individual over a period of time, being solely a volume measurement does not take tme and effort into consideration Thus an emphysematous patient may have a fairly large vital capacity but require increased time and effort to expel it The 3-second Timed Vital Capacity Test gives the maximal volume of the vital capacity that can be used by the individual (2)

$\begin{array}{cccc}\text { Normal values } & 1 s t \mathrm{sec} & 1 \text { st two sec } & \text { 1st three sec } \\ \text { \% V.C } & 83 \% & 94 \% & 97 \%\end{array}$

In the "Maximal Breathing Capacity Test," the volume of air that can be breathed as the maximal eftort, in one minute, is measured This gives information on ventilating efficiency of the respiratory muscles against normal and abnormal forces, resistant to the movement of the air in and out of the lungs

The "Formula of Motley" allows prediction of the values of "Maximal Breathing Capacity" for a given sex, age and body surface area:

$$
\left(F^{3}-\frac{\text { Age }}{2}\right) \times \text { BSA (Body Surface Area in sq metres) }
$$

The simple, standard exercise "step test," performed at the bedsıde will give a rough measure of disability in a patient suspected of suffermg from cardiopulmonary insufficiency The subject steps up and down on a $20 \mathrm{~cm}$ stool 30 times in one minute Moderate pulmonary or cardiac disease leads to dyspnoea for at least two minutes Severely handicapped patients remain dyspnoeic for several minutes Normal individuals show no significant dyspnoea

Knowing the individual's maximal breathing capacity and the amount of air breathed at rest over the same period of time (resting minute volume), an idea can be formed of that individual's breathing reserve

$$
\frac{\text { Maximal breathing capacity - Resting minute volume }}{\text { Maximal breathing capacity }} \times 100=\text { Breathing reserve }
$$

At rest, this amounts to 95-91 per cent of maximal breathing capacity, up to the fifth decade of life. During the first munte of rest following standard exercise, the breathing reserve is reduced to $88-70$ per cent in younger patients and 75-45 per cent in the older age group These values, obtained in healthy ind1viduals, may be appreciably changed in those suffering from cardio-respiratory

3Females $F=83$, males $F=97$ 
disease. The extent of reduction of the breathing reserve is of utmost importance to those who may plan to interfere in one way or another with diseased respiratory systems.

The choice of anaesthetic and conduct of anaesthesia will be based on the information gained from the history, physical exammation and those few tests. No chance should be missed to improve the existing respiratory disability even though the eradication of the factors responsible for the dysfunction is impossible.

Treatment of congestive heart falure with digitalis, salt restriction and diuretics goes a long way towards improving pulmonary circulation, allowing for faster curculation of the blood in the alveoli, diminished pulmonary hypertension and a dryer lung. Expansion of the lung can be improved by drainin 7 the co-existing pleural effusions or ascites. The haemoglobin and blood vo.ume should be brought as close to normal as possible, with blood transfusions, using whole blood or packed cells. Concomitant hypoxia has to rełeive attention with oxygen inhalation through a mask or through a nasal catheter $(12-18 \mathrm{~F}$.) with flows not less than 6-8 litres per minute.

Bronchial obstruction from secretions will have to be treated. Antrbiotics alone or in combination with aerosol sprays, contaming vasoconstractor drugs, do not always suffice. Postural drainage, catheter aspiration of the trachea through a bronchoscope, and restriction of cough-depressing drugs are often necessary. One reads more and more of the advisability of performing early elective tracheotomy in cases where clearing of the tracheobronchial tree gets out of hand with conservative measures. A.t this juncture, the anaesthetist's stand may well tip the scale of pros and cons Considerng that tracheotomy in no way interferes with subsequent conduct of anaesthesia, and that it rather faclitates the handling of the patient, one might think that he will favour the tracheotomy.

The value of preparation of asthmatic patients with cortisone is well established, and the value of Largactil as a premedication sedative without fear of respuratory depression has been stated.

\section{Case 1}

Mr R. P. G. (age, 56, weight, $160 \mathrm{lb}$.) suffered a fractured hip He was admitted late at nught. On admission it was noted that he had a marked breathing difficulty from asthima. His respiration was laboured, and expiratory wheezing and much grunting were present. He was slightly cyanosed about his lips. Patient's relatives stated that he spent most of his time in bed, unable to lie down on account of his asthma, which started four years previously, soon after a lobectomy operation for bronchiestasis. The Jatient had been conveyed to the hospital sittung in an armchair, the latter having jeen placed on top of a truck.

On examination, the patient's respiratory rate was $20 / \mathrm{min}$, his pulse was $120 / \mathrm{min}$., and his blood pressure 150/90. His breathing was mainly dashragmatic and his abdomen protruding. On auscultation generalızed rhonchi were heard but few rales were present. The breath sounds were farrly loud except on the lobectomy side, where they were either diminished or absent. The heart was not enlarged and there were no murmurs. There also were no signs of congestive heart failure. Marked finger-clubbing was noticeable. X-ray of the chest revealec no additional findings. EKG was essentially normal except for left ventricular preponderance. Laboratory data have shown slight leukocytosis to be present. 
The patient was placed in Fowler's position, and he would not allow any other position, and oxygen was started at 7 litres $/ \mathrm{mm}$. through at nasal catheter. He then was given Demerol $50 \mathrm{mg}$. and Largactıl $25 \mathrm{mg}$ mtramuscularly and Meticorten $2.5 \mathrm{mg}$. These allowed him to spend a farrly comfortable night. In the morning, the medication was repeated and when it took its effect, the head of the bed was gradually dropped to about $20^{\circ}$ from the horizontal There was no chanje in the pulse or respiratory rate.

Premedication consisting of Largactil $25 \mathrm{mg}$. anc Demerol $50 \mathrm{mg}$. was given intramuscularly in the afternoon and the patient's fractured hip was pinned under spinal anaesthesia, using oxygen 7 litres $/ \mathrm{min}$. and Neosynephrine intravenous drip (1 mg. per $100 \mathrm{cc}$ ) as supportives The patient tolerated the supine position and the operation very well

It is common knowledge that heavy cigarette smoking is associated with increased secretions and apparent over-activity of the mucosa of the upper resprratory passages These tendencies seem to jncrease following general anaesthesia leading to discomfort and posing the danger of atelectasis. There is little one can do, in the last day or two before the operation, in order to alleviate this threat An opinion has been expressed that smoking should be forbidden or curtalled to a minimum, for at least two weeks before the proposed operation This rule is most important in those facing abdominal or hernia operations

Certain conditions resulting from chest injuries demand immediate treatment to correct altered respiratory mechanics incompatible with life (3) In the open pneumothorax, when injury has caused a rent in the thoracic wall larger than the glottic openıng, a complete or near-complete collapse of the lung occurs and a "mediastinal swing," sufficient to interfere with expansion of the contralateral lung, takes place with each inspuration This "swing" also interferes with the venous return and the filling of the right heart, leading to a progressive fall in cardiac output, and aggravating shock It is imperative to re-establish negative pressure in the affected side in order to permit re-expansion of the lung and to abolish the "swing" of the mediastinal structures. The institution of positivepressure oxygen breathing and temporary dress-sealing of the wound are the first steps before any surgical action

In a crushed chest, or "stove-1n" chest, the rigidity of the chest wall is destroyed "Paradoxical respiration" may be present in this type of injury, when the involved area becomes indrawn on inspiration and protrudes on exprration. This may cause little or no air movement $\mathrm{m}$ and out of the chest, depending on the extent of the injury. Here again, immediate treatment is necessary to preserve life; assisted respiration with oxygen or air, and fixation of the injured side by strapping and making-the patient he on the affected side are the first-and measures which the anaesthetist may be called upon to perform.

The presence of varying amounts of blood in the pleural space is a rule rather than an exception when thoracic injury has occurred.

The loss of blood from a rent in the lung may be quite appreciable and, in some cases, out of proportion to the chest wall injury. It has occurred in at least two cases known to the author, in the absence of any penetrating chest wall injury

\section{Case 2}

Mr. R. A. M. (age, 36; weight, $160 \mathrm{lb}$.) suffered a gun-shot injury to his chest; on admission he was restless and apprehensive but not in shock. His blood pressure was 
$150 / 90$, Julse rate $90 / \mathrm{mm}$; respiration $24 / \mathrm{min}$., laboured on account of pain and associatec with haemoptysis There was surgical emphysema present extending to the neck and the patient's face was congested, but there was no cyanosis The movement of the left side of the chest was imparred. Large dressing prevented detailed exammation of this side of the chest. X-ray of the chest showed fluid density from the third rib down.

It was decided to establish an under-water dramage of the left pleural cavity and to explore and debride the wound in the chest wall Quick intubation under general anaesthesia was followed by the tollet of the trachea The patient was then turned on his side, injured side uppermost. Soon after, the debridement was started and it was then noted that the patient's blood pressure fell to $90 \mathrm{~mm} \mathrm{Hg}$ systolic and the pulse and respiration became more rapid. The pleura as yet not having been opened, it was sus jected that more than average cmount of bleeding occurred into the pleural cavity.

The left side of the chest was then opened through a wide incision and after the retractors were placed the lower lobe of the left lung was found to be ccllapsed and upwards of 1,000 ml. of blood was evacuated On inflating the collapsed_ung, a rent in the lingular lobe was identified Following the repair of the torn lung, the chest was closed and dramage of the pleural space instituted. Blood was replaced by transfusion during the procedure.

There was no evidence that the bullet had penetrated the parietal pleura

When the diagnosis of persistent haemorrhage into the pleural space is made, surgical intervention in order to control the bleeding is the only reasonable method of treatment. Prompt replacement by transfusion of blood lost should be concomitant with early intubation, preferably under topical anaesthesia, which will allow satisfactory toilet of the tracheobronchial tree Early tracheotomy should be considered if intubation proves difficult or is inadvisable for any reason (4).

Many surgical procedures on patients with less severe chest injuries may be performed satisfactorily under local or block-type anaesthesia

Treatment of shock, establishment of adequate arrway and correction of abnormal respiratory physiology are the most important steps before any further action is taken in thoracic injury.

\section{Heart and Circulation}

The number of patients suffering from heart disease, facing elective or emergency surgery, exclusive of surgery on the heart or great vessels, is steadily increasing on account of the longer survival rate of the general population Although these patients still represent a definite risk, particularly if other disorders are present, the majority of them go through surgery successfully. For instance, the mortality rate among those suffering from coronary insufficiency with a history of one or more episodes of acute coronary infarction, has fallen considerably as shown by the following reports (5).

$\begin{array}{rrl}1929 & 21.8 \% & \text { (170 cases) } \\ 1930 & 12.1 \% & \text { (414 cases) } \\ 1939 & 4.3 \% & \text { (259 cases) } \\ 1948 & 9.9 \% & \text { (311 cases) } \\ 1951 & 5.2 \% & \text { (58 cases) } \\ 1955 & 5.7 \% & \text { ( } 70 \text { cases) } \\ & 3.6 \% & \text { (111 procedures) }\end{array}$

Sprague

Butler and Feeney

Brummer and Williams

Morrison

Hannigan et al.

Baker, Gromer and Wise 
Improved anaesthetic management has certamly played a part in this progress Pre-anaesthetic evaluation, the knowledge of the nature of the dysfunction of the cardiovascular system and appropriate preparation constitute the better part of that management. Evaluation of the reserve based on clincal examination and history, supplemented by special tests, is the one single step of paramount importance

Inquiry into the performance of dally activities, the occurrence of shortness of breath or pain in the chest on exercise, nocturnal attacks of "asthma," frequent faintung and dizzy spells, a hrstory of prolonged periods of bed-rest during pregnancies on account of a "weak heart" will all throw much light on functional capacity and amount of actual disability

Careful attention pard during physical examination to the presence of venous congestion, basal crepitations, pre-sacral or ankle oedema, irregular pulse as well as dyspnoea or cyanosis will prove or disprove the presence of congestive heart falure Of whatever origin, this is the gravest complication, demanding energetıc treatment before any kind of surgery, elective or emergency Detection and treatment of early stages of congestive heart fallure will prevent its appearance on the operating table

In old people, the presence of slow, irregular pulse, particularly ${ }_{\mid}$if of long standing, is not taken with the same gravity that it is in young persons. However, rapid pulse, regular or irregular, due to fibrillation, frequent extrasystole, or paroxysms of the tachycardia calls for investigation as to the cause and approprate treatment before anaesthesia.

Marked dyspnoea and tachycardia lasting two or more. minutes following a simple standard exercise, as described under respiratory tests, shows the existence of cardiopulmonary inefficiency.

All this information is to be found right at the bedside with no more complicated equpment necessary than a pair of eyes and a stethoscope, and no amount of descriptive work in the chart will take its place The anaesthetist has to evaluate his patient for himself and must not rely entirely on notes, EKG reports or hearsay statement of optımistic nature.

The tangible evidence thus obtained by physical examination may then be measured agamst the unknown factors such as the effect of anaesthetic, the length of the operation, the amount of bleeding, the position on the table, etc In other words, the evaluation of the reserve must precede any discussion of the risk involved in undergoing surgery.

Knowledge of the nature of the heart disease and the amount of disability caused is indispensable in planning the treatment. The latter will be aimed at reducing incapacity to a minimum. Postponement of the operation altogether, on account of the heart disease, will seldom be necessary. In the presence of the actual emergency (perforated ulcer, ruptured gall bladder, intestinal obstruction or obstetrical emergency) one has to take the risk in order to save life.

In cases of recent myocardial infarction, it is suggested that at least six to eight weeks should elapse between the attack and surgery. The use of antcoagulants carries additional complications. Cessation of heparin will bring clotting to normal in a few hours. Dicumarol and Danilone have a more persistent 
action. Even so, the use of Vitamin $\mathrm{K}$ or Vitamin $\mathrm{K}$. oxıde will cut the waiting period.

The state of the myocardium must be improved in the presence of heart failure, aurıcular fibrillation, persistent tachycardia and rapid ectopic beats, with digitalis, Quinidine or Pronesthyl The choice of the drug will depend on the urgency of the case at hand. Rapid digitalization with Digoxin, Cedilanid, or Ouabain might have to be undertaken in emergency Anaemia should be treated with transfusion of whole blood or packed cells, hypoxia by early oxygen administration by face mask or nasal catheter Hypotension should be treated with Levophed or Neosynephrme contmuous intravenous drip, oxygen and blood transfusion. Dehydration and electrolyte imbalance should be treated by intravenous fluid and electrolyte therapy. Sec.ation should be accomplished with oral or rectal barbiturates, for example, Nembutal gr ${ }_{3}^{\prime}-1 \frac{1 \%}{2}$ Moderate amounts of morphine, Demerol, Pantopor or codeine may be given in the presence of pain, although there are those who would refrain from giving opiates. In the presence of tachycardıa, belladonna drugs may be omitted.

\section{Case 3}

Mr J P S. (age, 63, weight, $202 \mathrm{lb}$.), entered the hospital for the repair of a ventral hernia On admission, the patient was found to be.suffering from the congestive heart fallure The admission summary states that he was dyspnoeic, cyanosed and coughing, his heart was enlarged and a rapid fibrillation was present, blood pressure was $150 / 1$. 0 and the pulse rate over $100 / \mathrm{mmn}$., basal rales were heard bilaterally. Because of the patıent's obesity and vancose veins, it was not certam of he had distended neck vems or ankle oedema Fluoroscosy showed the enlargement of the left auricle and ventricle, the EKG confirmed auncular fibrillation and myocardial sschaemia The patient was put on the usual regimen for treatment of congestive heart falure which included low calorie and low salt diet and digitalization. When seen two weeks later at pre-anaesthetic rounds, he was free from dyspnoea at rest and also free from cough, he was fibrillatme but at a much slower a jical rate, and he was moving freely about the room. He hac. lost 12 pounds. The fol_owing morning, after Nembutal gr. 11/2 rectally and morphine gr. $\% \mathrm{~s} \mathrm{c}$ premedication, this patient underwent an uneventful operation for his hernia under continuous segmental spinal anaesthesia

Almost everything associated with anaesthesia and surgery is of necessity detrimental to the patient suffering from heart disease Every effort must be made to understand the problem and appreciate the steps taken by the surgeon and medical man in preparing the cardjac patient for operation. The patient's chance of surviving the operation will depend more upon this preparation than the actual technique of the anaesthesia employed (6)

The circulation on which the transportation of the oxygen to the tissues and the metabolites from the tissues to the lungs depends may be impaired at the heart level as described in the preceding section, and then our attention will be concentrated on that organ Very often, however, our concern is aroused by the knowledge of deleterious effects of reduced crrculatory volume of blood or of its fractions.

We know that stagnant anoxia and anaemic anoxia are by far the greatest hazards in surgery and its prevention is of prime importance to the anaesthetsst and surgeon alike We also know that the patient's immediate postoperative and 
subsequent recuperative periods will be influenced by the kind of attention given his curculatory deficits before the operation

An estumation of the degree of the deficit present is a part of safe pre-anaesthetic planning. One has to be gurded, of course, by the urgency of the case at hand, but, to use Bland's words, the polncy of hurrying slowly will frequently have a beneficial effect on the subsequent mortality and morbidity The occasions when the need for rapid preoperative preparations must be set above other considerations are relatively few. Usually we have more than enough time for proper evaluation and repaur of the existing deficits. For one reason or another that precious time may be wasted, elther through lack of appreciation of the possibility of deficit in the volume of blood or often through more hopeful than factual interpretation of the clinical and laboratory findings. It sounds superfluous to say that data giving the concentrations of haemoglobin, serum proteins or R B.C per $100 \mathrm{cc}$. of fluid may be misleading and may give a false sense of security Yet, generally speaking, these are still the only data avallable in most of the cases. This "routine" kind of evaluation of the patient's circulatory powers throws little light on the actual volume of the blood, proteins or R B C mass present. Clark et al. (7) have shown the existence of reduced blood volume, total haemoglobin and total R.B.C mass in malignant disease, chronic infections, peptic ulceration, hepatic disease and malnutrition commonly seen in elderly people, commensurate with the weight loss These losses were as follows

$\begin{array}{ll}\begin{array}{l}\text { Blood volume } \\ \text { Average total } \\ \text { haemoglobin }\end{array} & 67-79 \% \text { of standard value }=85 \mathrm{ml} / \mathrm{kg} \\ \begin{array}{c}\text { Average total } \\ \text { R B.C mass }\end{array} & 50-66 \% \text { of standard value }=127 \mathrm{gm} . / \mathrm{kg} \\ & 56 \% \text { of standard value }=40 \mathrm{ml} / \mathrm{kg}\end{array}$

These results, checked by Evans blue dye blood volume studies, were in agreement with the relationship existing between the body weight and the blood volume postulated by the authors, a relationship strong enough to permit the prediction of existing blood volume deficit on the basis of weight loss alone, without taking into account sex, age and body surface area.

The authors suggest that when taking information on weight loss from the patient, the optımal weight in health should be inquired for and taken as one point of reference They also feel that extremely obese, very tall and thin subjects, should have their blood volume deficit estımated on the basis of standard values for sex, age and body surface area rather than weight alone. They also point out that in gastro-intestinal bleeders, the values obtained tend to fall short of the actual loss sustaned.

\section{Case 4}

E C.S. (age, 64, we1ght, $134 \mathrm{lb}$ ), was admitted for gastrectomy following the diag,nosis of carcinoma o the stomach. His weight represented a loss of approximately 46 b. since his best weight one year previously was $180 \mathrm{lb}$ Takng into consideration the weight loss alone, this man was short of about $1,700 \mathrm{ml}$ of blood. The total blood volume estımation using Evans blue dye technique revealed no deficit to be present This finding could be correlated with the clnica appearance of the patient. Tall and of a large frame, he preserved his musculature quite well, despite weight loss. It could 
be visualized that any wasting that had taken place occurred in body. fat rather than the body muscle. The patient's physical power was little imparred and he carried his duties uninterrupted until his hospitalization.

To be on the safe side, the patient was given a transfusion of $500 \mathrm{ml}$. of whole blood before and $500 \mathrm{ml}$. during the operation, the latter to cover the operative blood loss. He withstood the four-hour operation very well and made a speedy recovery.

As their next logical step, Clark et al (7) undertook the quantitative replacement of blood volume deficit by whole blood transfusions before major operations and thus, they feel, they increased the tolerance of otherwise "poor risk" patients. There has been no evidence of untoward effects of overfilling the vascular space, and no complications have been attributed to mild haemoconcentrations.

J. P. Crehan (8) in an article on blood volume replacement in poor risk patients, writes: "In smaller institutions, where elaborate blood volume studies are not practical or avallable, this method of evaluating blood volume deficiency in surgical patients, on the basis of the weight lost, is more satisfactory than no method at all"

Risking repetition, one should like to remind that time is necessary for transfusing, sometımes large quantities of blood, into depleted patients. This calls for early planning of replacement by all concerned with the operative welfare of the patient.

There seems to be a little disagreement as to the necessity of restorng the curculating blood volume following acute haemorrhage. Most people also feel that blood is the best fluid to replace blood lost This may not always be possible but should always be strived for. This is adhered to not only because it seems so logical, but also because it stays in the circulation owing to the presence of the ied cells in the flud Red cells also make blood a preferable agent for transfusion because of their oxygen and carbon dioxide carryng capacity through the medium of haemoglobin and because of the latter's function as an important buffer system

Attempts have been made to establish a method for accurate assessment of acute internal or external blood loss. The usual criteria-blood pressure, pulse rate, pallor, coldness-are often masked in cases of compensated oligaemia. We know that latent shock may become apparent soon after induction of the anaesthesia, or when surgical interference or additional haemorrhage become superimposed.

It is seldom that we can see the actual amount of blood lost in an accident Therefore, any ready-to-use yardstick or rule of thumb, although not exactly "scientific," is of help when one attempts to measure the amount of blood lost Clark and Fisher of Birmingham Accident Hospital, in their recently published monograph (9) attempt to correlate blood loss with the size of the wound or the size of the swelling suspected to have been caused by haemorrhage. The authors have suggested that the flat of the hand or the size of the fist be used as yardsticks Thus, a wound the size of the flat of one hand corresponds to -approximately $500 \mathrm{cc}$ of blood, and a swelling the size of one first corresponds to an equal loss of blood To support haemodynamics and to prevent shock in severely injured patients we now have several measures at our disposal: (a) blood, plasma, or plasma expanders to increase volume; $(b)$ vasopressors to de- 
crease vascular lumen, $(c)$ short-term, quickly acting corticoids, such as soluble Hydrocortisone (Solu-cortef) for intravenous or intramuscular use; chlorpromazıne (Largactil) and sımilar autonomıc blockıng drugs protecting organism against deleterious reflexes.

\section{Case 5}

Mr. C V D H (age, 18, weight, $150 \mathrm{lb}$.) was thrown out of the truck in which he was riding and sustamed a severe in ury to his abdomen. He was admitted in shock, his blood pressure was non-recordab.e and most of his bowel outside the abdominal cavity. There was a segment of small bowel and a portion of the anterior abdominal wall missing altogether In addition, he had fractured several ribs and a clavicle. Subcutaneous emohysema was present

As first arc measures, the patient was given $1000 \mathrm{ml}$. of plasma, morphine gr. 1/ intravenously, and oxygen through a nasal catheter. He responded well to this treatment. When seen Jreoperatively, his blood pressure was $90 / 60$, pulse $120 / \mathrm{mm}$., weak, respiration $3 \mathrm{C} / \mathrm{mm}$. He was conscious and slightly restless. The resıratory movements of his chest were unequal, left side lagging behind the right. T.xe intensity of the breath sounds on the afected side was dimınished. There was at the time no displacement of the mediastinal structures.

Premedication consisted of Largactil $50 \mathrm{mg}$ and Demerol $50 \mathrm{mg}$. intramuscularly and atropine gr. 1/150 sc. First avallable blood $(500 \mathrm{ml}$ ) was given immediately before induction of the anaesthetic. For mantenance endotrachea $\mathrm{N}_{2} \mathrm{O} / \mathrm{O}_{2}$ mixture (3/3 litre/min.), Demerol intravenously (total $175 \mathrm{mg}$.). Neosynephrine intravenous drip (1 mg. per $100 \mathrm{cc}$ ) and an additional dose of -argactıl (25 mg.), were used. During the ojeration which lasted 21/4 hours, most of the small bowel was resected and the rent in the anterior abdominal wall was successfully closed The patient made a good, if stormy, recovery.

It is now well established that the adrenal-cortical steroids play an important role in adapting the organism to environmental changes and enable the patient to withstand stress brought about by the debilitating sickness, severe injury or overwhelming infections This they do in a reciprocal relationship with the secretions of the adrenal medulla (epinephrine) and the piturtary (ACTH).

The function of the adrenal cortices may be suppressed by trauma (haemorrhage into the adrenals), acute infection (Waterhouse-Friderichsen syndrome) or chronic infection, usually tuberculosis (Addıson's disease). However, in recent yeurs, another factor has arisen and has grown in importance with the widespread use of cortisone preparations for the treatment of diverse disorders. This factor, it is felt, by suppressing the normal adreno-cortical activity is responsible for unexpected episodes of shock at the time of stress, such as an operative procedure In the year 1952-3 there were several cases reported of fatal postoperatıve adrenal insufficiency involving patients who had recelved prolonged treatment with cortisone and who stopped taking cortisone before the operation. At necropsy, their adrenal cortices have been found to be atrophied.

Since that time several papers have been published on the subject, warning, of the inherent danger and giving advice on the preventive steps to be taken w_en contemplating operation on these patients. No clear-cut answer could be found to such questions as to what dose of cortisone administered over what period of time is necessary to produce adrenal-cortical suppression. Lundy and Pender of The Mayo Clinic $(10,11)$ consider that there is danger for anyone who has received cortisone within three to six months before the proposed operation, 
particular notice being given those who show symptoms of hyper cortinism (rounding of face, hypertension, peripheral oedema, hirsutism, pads of fat on the back of the neck). They seem to require special preparation unless they have had no cortisone for twelve months.

Any advice on how the extent of the adrenal-cortical depression may be determined before operation is tempered by mentioning that the tests available only measure separate functions of the adrenal cortex. There is no quantitative test to measure the amount of stress that the glands can cope with, and, of course, the stress imposed on an individual by various operations cannot be estimated.

Two tests are suggested as being both simple and available in all hospital laboratories (12). (a) In the Thorn Test (ACTH or eosinophil test) the adrenal cortex is stimulated, which is evidenced by a rapid fall in the circulating eosinophils. Failure to show a fall of 50 per cent or more, maximal in four hours, is considered to be a positive evidence of adrenal insufficiency.

(b) In the water-loading test insufficiency is shown by inability to produce a prompt diuresis after a rapid consumption of $20 \mathrm{ml} . / \mathrm{kg}$ of water

Estimation of the urinary excretion of cortico-steroids and 17-keto-sterolds, although reliable, can not be obtamed in most general hospital laboratories. If the operation is an elective one, $200 \mathrm{mg}$ of cortssone (100 $\mathrm{mg}$ in small children) should be administered intramuscularly 48,24 , and 1 to 2 hours before the operation Prolonged fasting (late slating) and morphine are contraindicated Premecieation should be one-half of that prescribed normally for the same age and we ght

If the operation is to be performed as an emergency procedure, $200 \mathrm{mg}$. of cortisone should be administered intramuscularly and $100 \mathrm{mg}$. intravenously. More cortisone should be given intravenously during the operation if necessary.

The problem of adrenal insufficiency must then be faced in surgical patients who are known to suffer from chronie adrenal insufficiency, or who are suspected of having therr cortices depressed by previous cortisone therapy. The presence of relative adreno-cortical insufficiency should also be suspected and the patient treated accordingly when shock develops without a readily demonstrable cause and the patient fals to respond to the usual resuscitative measures.

In such cases, cortisone should be administered intravenously as described above For controlling hypotension, $4 \mathrm{mg}$. of norepinephrine (Levophed) or 5-10 mg of Neosynephrine added to 1 litre of salne or 5 per cent glucose in saline solution should be administerèd Plasma or plasma expander may be added to increase the circulating blood volume.

\section{Case 6}

Miss M.M. (age, 73, weight, $110 \mathrm{lb}$.), an elderly woman of rather frall constitution, had been hit by an automoblle one afternoon and as a result suffered fracture of the forearm and ankle, the latter associated with much brussing and swelling of the leg. She was pale and in pain on admission, but not in shock Her blood pressure was 130/90, pulse 60/min., respiration 20/min. Following medication, plaster of Paris casts were appled in order to immobilize the broken limbs, no attempt being made to reduce the fractures until the patient's general condition improved and the swelling subsided. The patient's general appearance did not improve, although she remained conscious and did not complain of pain Several hours after the admission, the blood pressure steadily began to fall, but the pulse rate did not change. Then $500 \mathrm{ml}$. of whole blood was 
started, but as no visible improvement occurred, the transfusion was combined with intravenous infusion of Neosynephrine $1 \mathrm{mg}$. per $100 \mathrm{cc}$. This raised the systolic blood pressure from 60 to $100 \mathrm{~mm} \mathrm{Hg}$. However, the satient's blood pressure showed an immediate tendency to fall with slowing of the rate $o_{-}$the infusion, and she remained pale and apathetic. As the state of irreversible shock was feared to exist, $100 \mathrm{~mJ}$. of Solu-cortef was injected intravenously. This produced much improvement in the patent's ajpearance, her skm began to feel warmer, and blood pressure rose to $118 / 60$ with Neosynephrine intravenous drip running at a very slow rate; the patient spent a comfortable night. In the morning, the Neosynephrine drip was discontinued, only $2 \mathrm{mg}$. of the drug having been used curing the night, as against the $35 \mathrm{mg}$ used up in two hours preceding the administration of the cortisone

A W. Friend in his recent article on the subject of cortisone-induced adrenal suppression (12) draws attention to perhaps the rnost important aspect of this problem, namely, forehand knowledge of the possibility of such a state. He urges anaesthetssts to be on the look-out for cortusone-treated patients who might have been taking cortisone preparations up to the last day before admission to hospital for elective surgical procedures. Sometimes, he points out, the information cannot be obtained from the patient Then, he feels, it is the responsibility of the family doctor or anyone else prescribing cortisone drugs to provide the patient with a card clearly stating that that patient is or has been taking cortisone

There is no reserve of fluid or electrolyte in the body which can be dalled upon when abnormal losses disturb the body balance. Imbalance in body fluid and electrolyte may occur as a result of shock, trauma, burns, gastric suction, vomitung, diarrhoea, and in such states as carcinomatosis, nephritis, diabetes and acute llness, such as pneumonia In each case, losses are different in amount and nature.

The anaesthetist must make sure that his patient is in proper fluid and electrolyte balance before undertaking administration of the anaesthetic This means that he must be on the alert for the existence of flud and electrolyte imbalance, particularly in the very young and old Further, he must be able to interpret clinical findings and data obtained from special tests.

The history should determine the amount and the type of flund lost, the amount of fluid and food taken over the same period of time, whether thurst is present, and whether the patient has been perspiring a lot, has fever, feels weak, or is depressed

The study of a patient's chart will enable the inquiring anaesthetist to sum up the amount of fluid lost and gained Parenteral fluid is usually accurately measured, oral food can be estimated as fluid on the basis of approximately 70 per cent of its weight Volumes of urine, gastric suction and vomiting are nearly always entered on the chart. To these must be added a rough estmate of the fluid passed from extensive burns, discharges and fistulae There also must be added insensible obligatory losses (respiration, perspiration), which can be estimated on the basis of $07 \mathrm{cc}$ per $\mathrm{kg}$ per hour when no fever is present and additional 01 per $\mathrm{kg}$. per hour for each $2^{\circ} \mathrm{F}$ of fever

Simple water and sodium chloride depletion is the commonest, and hence the most important of the fluid and electrolyte problems seen clinically In dehydration, the water loss is always associated with electrolyte loss and vice versa. The changes in intracellular electrolyte structure are always secondary to 
initially untreated alteration in water and electrolyte in extracellular compartment.

In pure water depletion due, for example, to lack of intake for one reason or another, the extracellular flund becomes hypertonic. In order to maintain 1sotonicity, water flows from the intracellular compartment into the extracellular. In other words, the dehydration occurs at the expense of the cells. As obligatory water losses through the skın and lungs contmue unimpeded, and as kidneys working at therr maximum concentrating power still require at least $500 \mathrm{ml}$. daily to excrete about $35 \mathrm{gm}$ of total solids, death would occur, under ideal conditions, on the seventh to tenth day of complete water deprivation

Urinary output is reduced and urme is of high specific gravity; plasma sodium and chloride rise above normal, the blood urea is increased, the plasma volume remains unchanged untl late Thirst occurs early and persists, salivation decreases and dry mouth is a prominent symptom, there is progressive lassitude and hallucinations and delurium may occur There is no postural fainting and there is no nausea, vomitng or cramps

In the treatment of this type of dehydration, as in any other, prevention is most important / Those whose disease decreases their intake of water and food, or depresses the concentrating power of their kudneys, should have their water deficit made good by oral or intravenous adminıstration of 5 per cent glucose in water The administration of salıne is contraindicated, as it would only add salt to alreadý over-concentrated extracellular compartment The guide to rational therapy is increasing urine volume, fall in blood urea and improvement in clinical appearance.

The sodium chloride balance is maintained by keeping intake above output and excretion of excess in the urine Negative balance occurs owing to losses via the skin in sweat, by excessive gastro-intestnal discharges or inordinate loss in the urine in adrenal insufficiency Simple restriction of sodum chloride intake only very slowly produces deficiency of any consequence, but a low intake in patients who are already suffering from losses by diarrhoea, vomiting, or Wangensteen suction, may become very inportant. In sodium chloride deficit, the kidney practically ceases to excrete the needed salt and conserves it much more readily than water. Sodum and chloride losses ultmately produce a fall in the osmotic pressure of extracellular compartment fluid, and with continuing renal water excretion, the extracellular compartment loses volume. If disorder is allowed to advance, in an attempt to maintain isatonicity between the two compartments, potassium may enter the extracellular flurd, whence it is promptly lost in the urine. The picture thus progresses from bad to worse and eventually any electrolyte abnormality is conceivable If the amounts of sodium and chloride lost are isotonically not equivalent, acid-base balance will be altered.

Urinary volume remains unchanged providing an adequate water intake has been maintained, urine is of low specific gravity; urinary chlorides are absent, the blood volume is decreased and there is haemoconcentration, the blood urea is raised. In advanced cases of salt depletion, serum sodium, chloride and potassium are reduced and $\mathrm{CO}_{2}$ combining power changed accordungly with the acidbase imbalance present 
ClinIcally, lassitude, orthostatIc famting and headache are early symptoms. There is no thirst, the skm becomes inelastic and feels dry; vomiting, nausea, and cramps are present, the blood pressure falls and eventually shock supervenes with cold clammy skin, pallor, narrow pulse press ure, stupor and coma

If bowel atony, nausea and vomIting are absent, water and salt solutIons can be given by mouth. If the intravenous route IS to be used and if the condition is advanced, hypertoDlc salIne, for example, 5 per cent sodIUm chloride is adVISable. With the SIgns of clImcal Improvement, and WIth the reappearance of chloride in the urine this should be substItuted WIth IsotOnic or hypotonic sahne, for example, $500 \mathrm{ml}$. of 5 per cent glucose 111 water mIxed with $500 \mathrm{ml}$. of normal salme. The use of hypotonic sahne $\mathrm{m}$ genatnc patients IS partIcularly recommended The chmcal pIcture, the serum sodium, the urinary volume and unnary chlorides are the best gUIdes to treatment.

RelatIvely greater chloride than sodium deficit may result from loss of gastrIc secretIons by vomIting, leadmg to alkali excess, that IS, metabolic alkalosis. In such mstances, sodium shifts to the intracellular compartment and pot!assIUm to the extracellular compartment, potassium bemg dIsplaced by sodIUm excess Agaill, potaSSIUm WIll be lost in the urine if water loss has not been too great, or if water alone IS used for replacement therapy.

A solutIon contammg relatively more chloride than sodIUm should be selected to whIch potaSSIUm has been added If alkalosis and further potaSSIUm chlonde loss are to be prevented Such solutIons are Baxter's Travert 10\%-Electrolyte No 3, Darrow, and Butler paedIatnc solution, or It can be made by addmg $1 \mathrm{gm}$. of potaSSIUm chlonde (13 $4 \mathrm{mEq})$ to 1 htre of normal salme

Only rarely, $m$ advanced alkalOSIS (for example, when cyanOSIS IS present), ammonum chlonde as 2 per cent solution WIll have to be gIven mtravenously to proVide excess of chloride IOn PotaSSIUm losses depend on other electrolyte and water changes The defiClency of the IOn may occur ill alkalOSIS, as mentIoned $\mathrm{m}$ the precedmg paragraph, and $\mathrm{m}$ aCIdOSIS, for example, dIabetIC aCIdOSIS, $\mathrm{m}$ loss of intestmal and gastnc secretions, 111 too vigorous admmistratIOn of cortIsone drugs or intravenous therapy of glucose and sahne; ill "stress" SItuatIOns associated with anOXIa and shock, in tIssue destruction by trauma or dIsease, that IS, with negatIve mtrogen balance

Low serum potaSSIUm IS always taken as eVIdence of depletIOn of mtracellular potaSSIUm. Normal or 111gh serum potassium levels, however, are not always representatIve of normal potaSSIUm level in the cells, because of the lOme shifts previously descnbed

ClImcal symptoms and electrocardIOgraphic changes are the result of the low serum potaSSIUm. Muscular weakness with diminished or absent reflexes IS one of the earlIest mamfestatIons Intestmal dIstenSIOn not respondmg to ordmary measures also occurs early As the deficiency progresses, gasping respIratIon due to weakness of the reSpIratory muscles appears, together with the irregular pulse, mcreasing pulse pressure, venous distension and eventual heart faIlure from ventncular dulatation.

The electrocardIOgraphIC changes conSIst of prolongation of the Q-T mterval, low wide $\mathrm{T}$ waves, and low voltage. Later the S-T segment becomes depressed 
and "through" like, and T-wave is inverted. Premature beats appear and atrioventricular heart block follows.

As noted before, treatment of hypopotassaemia entails treatment of the total water and electrolyte imbalance. Potassium should be added in $13.4 \mathrm{mEq},-60 \mathrm{mEq}$. dose to repair solutions with $80 \mathrm{mEq}$./day as the maximum Jarenteral amount. The risk of producing dangerous hyperpotassaemia should be borne in mind, particularly in the presence of circulatory failure and renal insufficiency. Potasslum is contraindicated in oliguria of whatever origin. The presence of potassium in transfused plasma and whole blood should not be overlooked, especially when banked blood or plasma are used.

The electrocardiogram, blood and urine studies and frequent clinical evaluation are the best guides to safe potassium therapy (13)

\section{ConCLUSION}

Evidence has been presented for the necessity of clinical evaluation of patients, far ahead of planned anaesthetic and surgical interference. Recognition of particular problem should be followed by approprate preparation of the patient, the anaesthetıst takıng actıve inter est in that preparation.

\section{RÉSUMÉ}

En anesthésie, aujourd'hui, les troubles cardio-pulmonaires et crrculatoires consécutufs à la maladie ou aux blessures deviennent les problèmes les plus fréquents. L'apparition de nouveaux médicaments pouvant influencer l'homéostasie tout en nous procurant des armes nouvelles n'a pas été sans faire naître également de nouveaux dangers

Le médecin anesthésiste dott reconnaître le caractère et l'importance du trouble dans les systèmes vitaux de l'organisme. Pour atteindre ce but, il lui faut faire un examen physıque complet et s'aider de certames épreuves faciles qui peuvent être faites dans tous les hôpitaux ordinarres.

En plusieurs occurrences, il est nécessaire de prendre du temps pour préparer adéquatement un malade, qu'il s'agisse de transfusions à donner, d'équilibre hydrique ou électrolytıque à rétablir, de drannage des voies respiratoires ou de digitalinisation. Il est du ressort de l'anesthésiste de surveiller que l'institution de ces trattements ne soit pas retardée jusqu'à la veille de Iopération. Il s'impose également qu'il comprenne ces traitements et devienne familier avec eux pour en contınuer l'application le jour de l'opération

\section{REFERENCES}

1 Motley, H. L Oxygen Therapy. Veteran Administration T B (Dec. 31, 1953)

2 Nathan, A., \& Scialit, V A Cardiopulmonary Function-Range of Normals. Anesthesiology 5 (1955)

3 Gray, H K. Management of Traumatic Lesions of the Thorax. J. Iowa M Soc (March, 1954)

4 Hulman, S Tracheotomy for Flal Chest Lancet 454 (1957). 
5 Bellett, S Preoperative Preparation of the Patient with the Coronary Artery Disease Anesthesiology 3 (1956).

6 Pender, J W Anesthesia for Patient with Cardiac Disease Wis. M. J. (June, 1954).

7. Clark, J H, et al Chronic Shock Ann Surg (May, 1947').

8. Creenan, I $P$ The Value of Blood Volume Determingtion in the Poor Risk Patient Surg. Clin. North Amenca (June, 1954) Philadelshia. Saunders (1954).

9 Clark, M \& Fisher, J Birmingham Accident Hospita. Monograph on Blood Replacement Birmingham (1957)

10 Pender, J W. Complications in Anesthesid Related to Cortisone Therapy. Wisc. M. J (March, 1954)

11 Lundy, John S Cortisone Problems involving Anesthesia Anesthesiology 4 (1953)

12 Friend, A W Preventing Trouble with Cortisone diring Anesthesia and Surgery Postgrad. Med 2 (1957).

13 Bland, J H The Clmical Use of Fluid and Electrolyte Philadelphia Saunders (1952) 